\title{
Briefings
}

\section{Literature search from home}

\author{
M. S. Elameer, Consultant Psychiatrist, St David's Hospital, Carmarthen, \\ Dyfed SA31 3HB
}

British Medical Association members are now able to use a new service to doctors which, until recently, has been largely exlusive to libraries in big hospitals and other institutions. At the time of writing, the BMA Library Dial-Up Medline Project has just completed its pilot stage and is due to be launched formally at the beginning of June. Trials started in November 1992 and the system is now up and running.

\section{Medline}

Medline is the database produced by the American National Library of Medicine which covers the fields of medicine, nursing, dentistry, veterinary medicine and preclinical sciences. It contains bibliographic citations to articles from 3,500 of the world's leading medical periodicals, but not the full text of the articles themselves. The entire database consists of over seven million citations covering medical literature from 1966 to the present. The database is updated monthly and can be searched in segments (e.g. 1989 to present). Most of the citation entered after 1975 contain abstracts.

Medline's superior indexing and structure make it not only the premier medical database but probably the finest database in any field. Searching the database is done under more than 14,000 medical subject headings (MeSH). "Trees" of carefully defined headings ensure easy access to narrower subjects. Variations of medical terms are catered for in the indexing of subjects (e.g. myocardial infarction, heart attack, or attack on the heart can be used interchangeably). Users can search specific journals, look for named authors or specific text words and can combine or limit the results of several searches according to set criteria.

\section{Requirements to access the system}

Members with an IBM or compatible computer, a free serial port, a modem and communication software can access the new Library using their ordinary telephone lines. A fast printer and plenty of paper are essential for those who prefer to see their results on paper rather than a flickering monitor screen. A detailed description of the hardware involved has been provided in the Psychiatric Bulletin (Johnson \& Wells, 1992).

\section{Searching the database}

Once a user has accessed the CD-Plus Medline system he is guided by simple and friendly menus. An on-line tutorial is available for first-timers $(30+$ minutes) and advanced users can bypass the menus for faster and more flexible direct commands. After two or three minutes' searching time, downloading a list of 80 papers (most with good abstracts) takes approximately three further minutes. Users need pay nothing except their telephone costs at the usual rate. Once the call is terminated, the results can be read using any wordprocessor which can read DOS files, or printed through a simple "Copy (file) $1 \mathrm{ptl}$ " DOS command (assuming the printer is connected to parallel port 1).

\section{Personal experience}

I have been accessing the database both from home (using an Austin 486/33 computer with a hard disk and a Falcom FMC 2400 modem), and from our day hospital (using an Elonex 386/33 computer with a hard disk, and a Hayes Smartmodem 2400). The first arrangement offers a slightly smoother and faster access. Unlike the Falcom, the Hayes modem we use does not allow ordinary incoming telephone calls to pass through, which can prove problematic particularly at work.

I am a novice to on-line communications but was able to access the library using Procomm Version 2.4.3 software (shareware). After some difficulties in down loading the results of my searches, I decided to buy the recommended software, PcAnywhere ( $\$ 89$ + VAT). Some retailers sell the cheaper "remote" part of the software alone, which is sufficient for those who have no desire to expand their "communication" skills. "PcAnywhere" has proved to be a user-friendly software, and I have been using it successfully for over three months without unpacking the instruction book! Other software which can be used to access the service includes CrossTalk MK.4, Telix and VersaTerm (for the Macintosh interface). 
One unexpected effect for me of having ready access to a vast number of interesting abstracts has been to greatly increase, rather than reduce, the number of visits I make to the hospital library as I search for the full papers.

The impact of this service on my and our day hospital telephone bills is yet to be seen. What is certain is that this is an immensely powerful tool which is likely to contribute to great advances not only in the fields of research and education but also in direct patient care.

Interested readers can write to either Mrs Jane Rowlands or Mr William Forrester of the BMA Medline Project, BMA Library, BMA House, Tavistock Square, London WC1H 9JP.

\section{Acknowledgements}

I am indebted to both Mrs Rowlands and $\mathrm{Mr}$ Forrester for their helpful comments, information and support.

\section{References and further reading}

JOHNSON, B. A. \& WELLS, L. T. (1992) Basics and purchasing tips. Psychiatric Bulletin, 16, 703-708.

LitTlejoHNS, C. S. (1990) Computer communications in psychiatry and literature searching. Psychiatric Bulletin, 14, 413-415.

Williamson, D. J. (1992) An introductory course. Computers in psychiatry. Psychiatric Bulletin, 16, 504-505.

\title{
Launch of the National Register of Psychotherapists
}

\author{
Thomas Fahy, Assistant Editor, Psychiatric Bulletin
}

In the imposing surroundings of the Moses Room in the House of Lords, the United Kingdom Council for Psychotherapy (UKCP) launched its first National Register of Psychotherapists on 20 May 1993. Or rather, celebrated the launch of the Register, as one of the arcane rules of the "other place" is that official launches of such documents cannot take place in the building. These regulations were brushed aside in a successful and upbeat meeting attended by representatives of the Council, politicians and members of the press.

The Register gives details of approximately 3,000 psychotherapists who are members of organisations which have been accredited by the UKCP. This publication represents the culmination of 22 years of work. Pressure for a Register of Psychotherapists was first mooted by the Foster Report in 1971 which detailed examples of the abuse of psychotherapy in the Church of Scientology. This report concluded that there should be legislation to control psychotherapy in the UK. In 1975 a Working Party on Statutory Regulation of Psychotherapists was set up and reported three years later recommending the setting up of a Psychotherapy Council which would register and enforce standards of practice. Further pressure for change came from Graham Bright MP who introduced a Bill to the House of Commons in 1981 to regulate the practice and profession of psychotherapy. Although the Bill fell at the second reading, Mr Bright has continued to campaign for a registration system. The most significant developments in the background to the Register occurred in 1982 when the British Association for Counselling organised a symposium with the aim of furthering discussion of the matter. This led to annual meetings until 1989 when the United Kingdom Standing Conference of Psychotherapy (UKSCP) was inaugurated. In 1990 the UKSCP delegates voted to form a register. A process of tortuous negotiation between the different psychotherapy bodies finally culminated in the publication of the National Register.

Emmy Van Deurzen-Smith, Chair of the UKCP, introduced the Register. Bringing the different psychotherapy bodies together had been a complex strategic operation, rather like bringing together the world's religions. However, the officers of the UKCP hoped that the document would help to redress public ignorance of psychotherapy and improve access to good psychotherapists. The reputation of psychotherapy had been tarnished by the ease with which any self-appointed psychotherapist could open his or her door to vulnerable members of the public. Press attention to instances of misbehaviour by psychotherapists emphasised the importance of the profession establishing clear ethical guidelines and effective disciplinary procedures. Graham Bright MP said that his initial concerns about the 